\begin{tabular}{cc|c}
\hline Tar. Bil. Der. & Journal of Agricultural Sciences \\
& $\begin{array}{c}\text { Dergi web sayfası: } \\
\text { www.agri.ankara.edu.tr/dergi }\end{array}$ & Journal homepage: \\
& www.agri.ankara.edu.tr/journal
\end{tabular}

\title{
İstavrit Balığı (Trachurus mediterraneus Steindachner, 1868)'nın Doğu Karadeniz'de Kafeslerde Büyüme Performansının Belirlenmesi
}

\author{
Nadir BAŞÇINAR ${ }^{\mathrm{a}}$, Fatma Delihasan SONAY ${ }^{\mathrm{b}}$, Şahin ALSAN", İlhan ALTINOK ${ }^{\mathrm{a}}$ \\ ${ }^{a}$ Karadeniz Teknik Üniversitesi, Sürmene Deniz Bilimleri Fakültesi, Balıkçılık Teknolojisi Mühendisliği Bölümü, 61530, Çamburnu, Trabzon, \\ TÜRKIYE \\ ${ }^{\boldsymbol{b}}$ Recep Tayyip Erdoğan Üniversitesi, Su Ürünleri Fakültesi, Su Ürünleri Yetiştiriciliği Bölümü, 53100, Fener, Rize, TÜRKIYE \\ ${ }^{c}$ Doğu Karadeniz Kültür Balıkçılığı A.Ş. (DOKABAŞ), 61250 Yomra, Trabzon, TÜRKIYYE
}

ESER BILGİisi

Araştırma Makalesi DOI: 10.1501/Tarimbil_0000001379

Sorumlu Yazar: Nadir BAŞÇINAR, E-posta: nbascinar@gmail.com, Tel: +90 (462) 3778082

Geliș Tarihi: 22 Mayıs 2014, Düzeltmelerin Geliși: 17 Aralık 2014, Kabul: 12 Ocak 2015

\begin{abstract}
ÖZET
Bu çalışma istavrit balığının (Trachurus mediterraneus Steindachner, 1868) Doğu Karadeniz'de kafeslerde kültür potansiyeli üzerine yapılan ilk çalışmadır. Balıklar, ağ tuzaklarla doğadan yakalanmış ve doğrudan kafeslere transfer edilmiştir. Büyütme çalışması Ekim 2010 ile Ekim 2011 arasında yürütülmüştür. Ebatları 5x5x3 m olan kare kafes, birbirinden tamamen bağımsız eşit hacimli üç eşit küçük kafese $(5 \times 1,6 \times 1.5 \mathrm{~m})$ bölünmüş ve her bir küçük kafese yaklaşık 1000'er adet balık stoklanmıştır. Balıklar ticari deniz levreği yemi ile doyuncaya kadar elle günde iki kez yemlenmiştir. Çalışmanın başında $12.20 \pm 0.97 \mathrm{~cm}$ ve $24.09 \pm 3.25 \mathrm{~g}$ olan ortalama boy ve ağırlık değerleri çalışma sonunda $19.61 \pm 1.47$ $\mathrm{cm}$ ve $76.80 \pm 16.24$ g'a $(\mathrm{n}=100)$ ulaşmıştır. Ortalama yem değerlendirme ve yaşama oranları sirasıyla 2.33 $\pm 0.21(2.12$ 2.54) ve \% 95.58-98.59 olarak hesaplanmıştır. Bu sonuçlara göre, deniz kafeslerinde istavrit balığının su sıcaklığının 12 ${ }^{\circ} \mathrm{C}$ 'nin altına düştügü kış ayları haricinde büyüyebildiği sonucuna varılmıştır.

Anahtar Kelimeler: İstavrit balığı; Akuakültür; Yem değerlendirme oranı; Kondisyon faktörü; Yaşama oranı
\end{abstract}

\section{Growth Performance of Horse Mackerel (Trachurus mediterraneus Steindachner, 1868) Reared in Sea Cages at the Southeastern Black Sea}

\author{
ARTICLE INFO \\ Research Article \\ Corresponding Author: Nadir BAŞÇINAR, E-mail: nbascinar@gmail.com, Tel: +90 (462) 3778082 \\ Received: 22 May 2014, Received in Revised Form: 17 December 2014, Accepted: 12 January 2015
}

\begin{abstract}
This study is the first potential culture of the Mediterranean horse mackerel (Trachurus mediterraneus Steindachner, 1868 ) in cages in the Southeastern Black Sea. The wild fish was captured by net and transferred into sea cages. Growth study was performed between October 2010 and October 2011. Sea cage which $5 \times 5 \times 3 \mathrm{~m}$ dimensioned, was divided there equal volume $(5 \times 1,6 \times 1.5 \mathrm{~m})$ independent from the other, and the fish of approx. 1000 specimen was stocked in
\end{abstract}


per volume. Commercial seabass feed was used, and ad libitum feeding regime was set as twice a day. At the beginning, the experimental fish were $12.20 \pm 0.97 \mathrm{~cm}$ in length and $24.09 \pm 3.25 \mathrm{~g}$ in weight, and at the end of study, they reached to $19.61 \pm 1.47(\mathrm{n}=100) \mathrm{cm}$ in length and $76.80 \pm 16.24 \mathrm{~g}$ in weight. Average feed conversion ratio and the survival rate were calculated as $2.33 \pm 0.21$ (2.12 to 2.54), and 95.58-98.59\%, respectively. According to the results of this study, there is a potential for culturing horse mackerel in sea cages and fish grow trough out the year except winter when water temperature decreased to the $12^{\circ} \mathrm{C}$.

Keywords: Horse mackerel; Aquaculture; Food conversion ratio; Condition factor; Survival rate

(C) Ankara Üniversitesi Ziraat Fakültesi

\section{Giriş}

Karadeniz'de balıkçılığın 1980'li yılların sonunda yaşadı ̆̆ı kriz esnasında önemli teşvik ve beklentilerle başlatılan ă̆ kafeslerde balık yetiştiriciliği beklenen gelişmeyi gösterememiştir. Bunda ARGE çalışmaları gerçekleştirilmeden ticari düzeyde üretime başlanmasının yanı sıra Karadeniz'in hidrografik özelliklerinin (su sıcaklığı, kıyı yapısı, akıntı ve dalgalar) önemli payı vardır. Daha sonraki yıllarda bazı akademik çalışmaların yürütülmesine rağmen bunlar sektörel gelişimi yönlendirici seviyeye ulaşamamıştır (Başçınar et al 2013). Gerek talepteki artış gerekse ürüne sağlanan doğrudan destek nedeniyle mevcut işletmeler kapasitelerini artırma ve deneme-yanılma yoluyla yeni arayışlara başlamışlardır. Ancak, mevcut durumda yetiştirilen tür sayısında artış gözlenmemiştir. $\mathrm{Bu}$ nedenle tür sayısını ve yeni ekonomik yaklaşımların geliştirilmesi ihtiyacı doğmuştur.

İstavrit balığı Karadeniz'de hamsiden sonra en fazla av verimine sahip olan bir türdür ve gırgır tekneleri tarafından avlanmaktadır (Çelikkale et al 1999). İstavrit balığı üretim miktarı ülkemizde 1985-1990 yılları arasında yaklaşık 100 bin ton seviyelerinde iken oldukça hızlı bir şekilde azalmış ve 2009 yılında 28268 ton olarak gerçekleşmiştir (TUIK 2012). İstatistikler ve tür üzerinde yapılan çalışmalar, stoklar üzerinde av baskısının oldukça fazla olduğunu göstermektedir (Şahin et al 2009).

İstavrit balıkları üzerinde yürütülen çalışmaların büyük bir bölümü balıkçılık biyolojisi (Yücel \& Erkoyuncu 2000; Satılmış et al 2003; Şahin et al 2009; Özdemir et al 2009), işleme ve değerlendirme (Düzgüneş \& Karaçam 1991; Kartal et al 2003; Erdem \& Bilgin 2005; Patır \& İnanlı 2005), biyoekolojik çalışmalar (Samsun et al 2006; Yankova \& Raykov 2006) ve hastalık (Boran et al 2013) olarak görülmektedir. İstavrit yetiştiriciliği üzerine yapılmış bilimsel bir literatüre rastlanmamıştır. Halen istavritten döl alınmamış olması ve Gıda, Tarım ve Hayvancılık Bakanlığı tarafından türün avcılığa dayalı kafes yetiştiriciliğine izin verilmemiş olması önemlidir. Doğadan yavru toplanarak yapılan yetiştiriciliğin, balık stoklarını oldukça yıprattığı bir gerçektir. Ancak, türün üzerindeki av baskısı stoklardaki balık büyüklüğünü ve dolayısıyla pazar değerini (TL $\mathrm{kg}^{-1}$ ) azaltmaktadır. Av sezonunun başladığı Eylül ayının ilk haftalarında gırgır teknelerinin yoğun olarak avladığı türün istavrit olması, ardından palamut ve hamsi avcılığının başlaması ile av baskısının azaldığı görülmektedir. Av sezonunun kapanması ile (Nisan ayı), pazarlanabilir balık tür sayısı ve miktarında azalma yaşanmakta ve tezgahlarda rastlanan balık türlerinin büyük bölümünü kültür balıkları olan alabalık, deniz levreği ve çipura almaktır. Yetiştiricilikte sadece üç tür ile sınırlı kalınması, tüketici tercihinde sınırlanmalara, küçük balıkçılar tarafından avlanan doğal balıkların (istavrit, mezgit, zargana, kefal, barbunya gibi) fiyatlarında artışa neden olmakta ve balık tüketimi azalmaktadır.

Deniz kafeslerinde alabalıklar daha hızlı büyümesine rağmen (Korkmaz \& Kırkağaç 2008), nisan ayından itibaren hasat nedeniyle dolu kafesler sayısal olarak azalmakta ve haziran ayından sonra ise tamamen boşalmaktadır. Sevilerek tüketilen istavrit balığının boşalmış olan alabalık kafeslerinde 
besiye alınması, birkaç aylık semirtme ile yaz aylarında pazarlanması ile kültür balıkçılığının yıllık sürekliliği sağlanabilir.

$\mathrm{Bu}$ çalışmanın temel amacı; kültür şartlarında deniz levreği kafeslerine dışarıdan girerek büyüyebilen ve suni yem alımında problem göstermeyen (Başçınar et al 2013) istavrit balığının yetiştiricilik potansiyelini irdelemektir.

\section{Materyal ve Yöntem}

Saha çalışmaları (Bakanlık ile yapılan resmi yazışmalar gereği) 3/1 Numaralı Su Ürünleri Avcıllı̆ını Düzenleyen Tebliğ kapsamında (boy, zaman, avlanma yöntemi) yürütülmüştür. $\mathrm{Bu}$ nedenle çalışmada kullanılan istavrit balıkları Eylül ayında tuzaklarla yakalanmış ve kafes ortamına uyum sağlamaları beklendikten sonra Ekim ayında semirtilmeye başlanmış ve bir yıl sonra semirtme sonlandırılmıştır.

Çalışma, Doğu Karadeniz'de Trabzon İli Yomra İlçesi Derbent Burnu mevkiinde (Şekil 1) karadan 0.6 mil açıkta Doğu Karadeniz Kültür Balıkçılığı A.Ş. (DOKABAŞ)'ye ait işletmede yapılmıştır. Karadan denizdeki kafeslere gidiş ve gelişler servis tekneleri ile sağlanmıştır.

İstavrit balıkları doğadan Eylül 2010'da tuzak ağlar ile yakalanıp ilk önce 14 m çaplı HDPE (High Density Polietilen) malzemeden yapılmış 3 adet kafese stoklanmış, suni yeme bu kafeste alıştırma yapıldıktan sonra kontrolü daha kolay olan $5 \times 5 \times 3$ $\mathrm{m}$ ebatlarındaki ăg kafese transfer edilmiştir. Çalışmada ağ kafes; tamamen birbirinden bağımsız, balıkların kaçma, birbirine geçme ve yem geçişi olasılığını ortadan kaldıracak şekilde tekerrür oluşturma amacıyla yeniden dizayn edilmiş (ebatları $5 \times 1,6 \times 1.5 \mathrm{~m}$; kafes ağ $10 \mathrm{~mm}$ göz açıklığında ve ağın su üzerinde kalan kısmının yüksekliği 1 metre) ve kullanılmıştır. Ağın tabanına akıntılardan en az seviyede etkilenmesi amacı ile 8 kg'lık 8 adet ağırlık bağlanmıştır. Kafesin üzeri kuşlardan koruma amaçlı $30 \mathrm{~mm}$ göz açıklığında çift kat kuş koruma ağı ile örtülmüştür.



Şekil 1- Karadeniz'de büyütme kafesleri sahası

Figure 1-Grow out sea cages local in the Black Sea

Çalışmada ortalama boyu $12.20 \pm 1.01 \mathrm{~cm}$ ve ağırlığı $24.09 \pm 6.16 \mathrm{~g}$ olan balıklar bölmelere rastgele dağıtılmış, sırasıyla 999 adet, 1013 adet ve 1000 adet (toplam 3012 adet) olarak stoklanmıştır. Balıkların elle muameleye karşı hassas olmaları nedeniyle mümkün olduğunca el değmeden işlemler yapılmış, aynı zamanda atmosferik şartlar (rüzgar, akıntı, dalga) nedeniyle başlangıçta sayılar tamamen eşitlenememiştir.

Çalışmada Gıda, Tarım ve Hayvancılık Bakanlığı tarafından verilen şartlı izinler nedeniyle zorunlu olarak $1^{+}$yaşı istavrit balıkları kullanılmıştır. $\mathrm{Bu}$ nedenle kullanılan balıklar eşeysel olgunluğa ulaşmış durumdadır. Balıklarda yaş tayini otolitlerden yapılmıştır.

Araştırma süresince balıkların beslenmesinde ticari bir firma tarafindan üretilen $\% 48$ ham protein, \% 18 ham yağ ve $4400 \mathrm{kcal} \mathrm{kg}^{-1}$ metabolik enerji içeren $2 \mathrm{~mm}$ ekstrude deniz levreği yemi kullanılmıştır.

Araştırma, 09 Ekim 2010-18 Ekim 2011 tarihleri arasında 375 gün süreyle yürütülmüştür. Çalışmada 0 . (başlangıç), 31, 62, 93, 124, 157, 185, 213, $261,286,307,333$ ve 375 . (son) günlerde ölçüm yapılmıştır. Balıklar ölçüm öncesi fenoksietanol (50 mg L L $\mathrm{mu}^{-1}$ sule bayıltılıp sakinleştirilmiştir. Kafeslerde, su sıcaklıkları günlük, çözünmüş oksijen ve tuzluluk aylık olarak ölçülmüş; akıntı durumu, rüzgar şiddeti ve yönü, dalga yüksekliği ve bulanıklık izlenmiştir. Ayrıca kafes ağları haftada bir dalgıç tarafindan kontrol edilmiş, olası risklere karşı 
gözlem yapılmış, eğer varsa ölü balıklar düzenli olarak kayıt altına alınmıştır.

Balıkların tartımında sudan etkilenmeyen \pm 0.1 $\mathrm{g}$ hassasiyetli AND marka ve HL-300WP model terazi kullanılmıştır. Balıkların tam boyu $\pm 1 \mathrm{~mm}$ hassasiyetli cetvel, günlük sicaklık ve çözünmüş oksijen Oxyguard Gamma marka ve model cihaz ile ölçülmüştür.

Balıklar günde iki kez (sabah 08.00; akşam kışın 16.00 , ilkbahar ve sonbaharda 17.00 , yazın ise 18.00) olmak üzere doyuncaya kadar elle yemlenmiştir. Yem alma isteği kriter alınarak, yemleme esnasında balıkların hareketleri göz önünde bulundurulmuş, yem almaya karşı hareket azalınca yemlemeye son verilmiştir. Günlük olarak tüketilen yem miktarları kaydedilmiştir.

Yem değerlendirme oranı (FCR), ağırlıkça spesifik büyüme oranı $\left(\mathrm{SBO}_{w}\right)$, kondisyon faktörü $(\mathrm{K})$ ve yaşama oranı $(\mathrm{S})$ Eşitlik 1, 2, 3 ve 4'e göre hesaplanmıştır.

Yem değerlendirme oranı (FCR);

$\left.\mathrm{FCR}=\mathrm{F} /\left(\left(\mathrm{B}_{\mathrm{S}}+\mathrm{B}_{\mathrm{i}}\right)+\mathrm{m}\right)\right)$

Ağırlıkça spesifik büyüme oranı $\left(\mathrm{SBO}_{\mathrm{w}}\right)$;

$\mathrm{SBO}_{\mathrm{w}}=100\left(\left(\ln \mathrm{W}_{\mathrm{s}}-\ln \mathrm{W}_{\mathrm{i}}\right) / \mathrm{t}_{\mathrm{s}}-\mathrm{t}_{\mathrm{i}}\right)$

Kondisyon faktörü (K);

$\mathrm{K}=100\left(\mathrm{~W} / \mathrm{L}^{3}\right)$

Yaşama oranı $(\mathrm{S})$;

$\mathrm{S}=100\left(\mathrm{~N}_{\mathrm{s}} / \mathrm{N}_{\mathrm{i}}\right)$

Burada; F, bir periyotta tüketilen yem miktarı $(\mathrm{g})$; B, biyokütle $(\mathrm{g})$; m, ölen balıkların toplam ağırlığı (g); i, ilk değer; s, son değer; W, ağırlık (g); L, tam boy (cm); t, süre (gün); N, balık sayısı (adet)'dir.

\section{Bulgular ve Tartışma}

Çalışma sahasında yıllık ortalama tuzluluk \%o $15 \pm 1.09$; çözünmüş oksijen değeri ise $8.4 \pm 1.04$ $\mathrm{mg} \mathrm{L} \mathrm{L}^{-1}$ olarak hesaplanmıştır. Aylık ortalama minimum su sicaklığ $8.9 \pm 0.4{ }^{\circ} \mathrm{C}$ olarak Nisan ayında, maksimum $25.8 \pm 0.8{ }^{\circ} \mathrm{C}$ olarak Ağustos ayında belirlenmiştir. Çalışma süresince, dalga yüksekliği, rüzgar şiddeti ve yönü, akıntı hızı ve yönü, bulanıklılık izlenmiş, ancak kafes ortamı için tehlike oluşturacak seviyelere ulaşmamıştır.

Çalışmada kullanılan istavritler belirli aralıklar ile rastgele örnek alınarak, ortalama boy ve ağırlıkları ölçülmüştür. Çalışma başında ortalama boyu $12.20 \pm 0.97 \mathrm{~cm}$ ve ortalama ağırl $\breve{g ̆}_{1} 24.09 \pm 3.25$ $\mathrm{g}$ olan istavrit balıklarının çalışma sonundaki ortalama boyu $19.61 \pm 1.47 \mathrm{~cm}$ ve ortalama ağırlığ $76.8 \pm 16.24 \mathrm{~g}$ olarak hesaplanmıştır (Çizelge 1). Kış aylarında su sıcaklığındaki düşüşe bağlı olarak büyüme hızının azaldığı belirlenmiştir (Şekil 2).

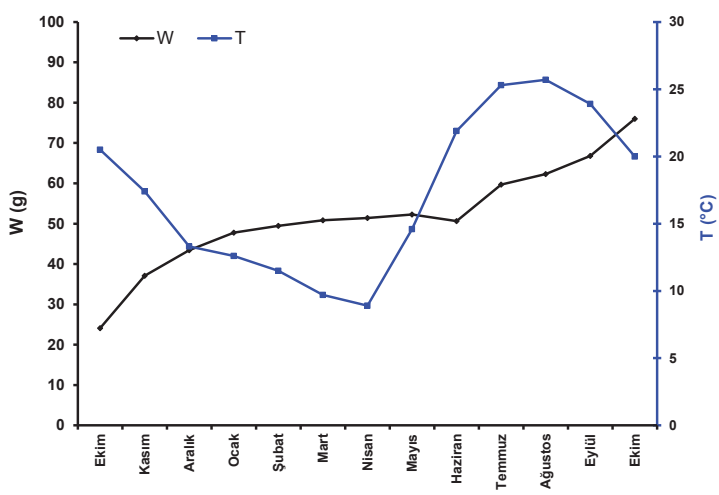

Şekil 2- Ekim 2010-Ekim 2011 arası istavrit balıklarının ağırık artışı ve ortalama deniz suyu sıcaklığı değişimi

Figure 2- Growth performance of Mediterranean horse mackerel and mean seawater temperature during the trial

İstavrit balığının Doğu Karadeniz şartlarında yem değerlendirme oranları incelendiğinde düşük ve yüksek su sıcaklıklarında daha yüksek değerler hesaplanmıştır. En düşük (en iyi) değer Ekim-Kasım 2010 döneminde $1.20 \pm 0.03$ olarak belirlenmiştir. Çalışma süresince hesaplanan ortalama yem değerlendirme oranı ise $2.33 \pm 0.21$ (2.12-2.54)'tür (Çizelge 1). 09 Mayıs-26 Haziran 2011 döneminde ise ağırlık kaybı meydana gelmiş ve bu nedenle yem değerlendirme oranı hesaplanamamıştır. Yapılan gonad incelemelerinde balıkların yumurtladıkları (Başçınar et al 2013) ve bu nedenle ağırlık azalması oluştuğu (SGRw= $-0.07 \pm 0.01)$ belirlenmiştir. 
Çalışma başlangıcında istavrit balıklarının kondisyon faktörleri ortalama $1.32 \pm 0.12$ (1.041.56) olarak hesaplanmıştır. İlerleyen periyotta ortalama kondisyon faktörlerinde artış gözlenmiştir. Kış aylarının gelmesi ile birlikte yem alımına bağlı olarak kondisyon faktörleri azalma eğilimine girmiştir. İlerleyen aylarda ise boyca büyüme oranının, ağırlıkça büyüme oranına göre daha fazla olması nedeniyle kondisyon faktöründe düşme gözlenmiştir (Çizelge 1).

Çalışmanın ilk ve ikinci periyotlarında, ağırlıkça spesifik büyüme oranları en yüksek değeri sergilemiştir. Su sıcaklığındaki azalmaya bağlı olarak yem tüketimi ve dolayısı ile büyüme oranı azalmıştır (Çizelge 1). Çalışma sonunda boyca ve ağırlıkça spesifik büyüme oranları sırasıyla $0.127 \pm 0.011$ ve $0.305 \pm 0.001$ olarak hesaplanmıştır. Ağırlıkça büyüme oranı döl verimi nedeniyle beklendiği gibi 213-260. gün periyodunda negatif olarak gerçekleşmiştir (Başçınar et al 2013).

Çalışma süresince ölen balıklar toplanmış ve kaydedilmiştir. En fazla ölen balık kasım ayında gerçekleşmiştir. Çalışma süresince yaşama oranı ortalama \% 97.42 \pm 1.61 , ölüm oranı $2.58 \pm 1.61$ olarak hesaplanmıştır.

İstavrit ile ilgi yapılan önceki çalışmalar balığın morfolojik, biyolojik, ekolojik özellikleri, avcılık ve işleme konuları üzerinedir, ancak yetiştiricilik ile ilgili bilimsel bir çalışma ise daha önce yapılmamıştır.

İstavrit balıkları ile ilgili olarak populasyon dinamiği üzerine yapılan çalışmalar, balıkların yaz aylarında ürediğini ve bir yaşında eşeysel olgunluğa ulaştığını ortaya koymuştur (Genç et al 1998), dolayısıyla yasal av boyu, ilgili tebliğ gereği olarak $13 \mathrm{~cm}$ olarak belirlenmiştir. $\mathrm{Bu}$ araştırmada kullanılan balıkların ortalama başlangıç boyu belirlenirken bu kritere uygunluğa özen gösterilmeye çalışılmıştır ve balıklar bir yaşını doldurmuştur. Bir yaşını dolduran Trachurus mediterraneus için ortalama boy daha önce 12.66 $\mathrm{cm}$, ağırlık $13.72 \mathrm{~g}$ (Şahin et al 2009), $13.83 \mathrm{~cm}$ ve $20.80 \mathrm{~g}$ (Genç et al 1998), Trachurus trachurus için ise bu değerler $11.96 \mathrm{~cm}$ ve $14.26 \mathrm{~g}$ olarak

Çizelge 1- Ortalama boy $(\mathrm{L} ; \mathrm{cm})$, ağırlık (W; g), kondisyon faktörü (K) ağırlıkça spesifik büyüme oranı (SGRw) ve yem değerlendirme oranı (FCR) değerleri $( \pm s d)$

Table 1- Mean length ( $L ; \mathrm{cm})$, weight (W; g), condition factor $(K)$, specific growth rate in weight (SGRw), and food conversion ratio $(F C R)$ values $( \pm$ sd)

\begin{tabular}{rccccc}
\hline Gün & $L(\mathrm{~cm})$ & $W(\mathrm{~g})$ & $K$ & $S G R w$ & $F C R$ \\
\hline 0 & $12.20 \pm 0.97$ & $24.09 \pm 3.25$ & $1.32 \pm 0.12$ & $1.45 \pm 0.02$ & $1.20 \pm 0.03$ \\
30 & $13.37 \pm 0.19$ & $37.03 \pm 0.50$ & $1.54 \pm 0.09$ & $0.51 \pm 0.01$ & $2.73 \pm 0.42$ \\
61 & $15.12 \pm 0.02$ & $43.40 \pm 0.51$ & $1.25 \pm 0.02$ & $0.24 \pm 0.05$ & $2.14 \pm 0.86$ \\
92 & $16.25 \pm 0.23$ & $47.76 \pm 2.49$ & $1.11 \pm 0.05$ & $0.19 \pm 0.07$ & $3.72 \pm 1.03$ \\
123 & $16.33 \pm 0.14$ & $49.93 \pm 1.05$ & $1.14 \pm 0.02$ & $0.05 \pm 0.01$ & $2.83 \pm 0.42$ \\
156 & $16.92 \pm 0.17$ & $50.83 \pm 1.07$ & $1.05 \pm 0.04$ & $0.02 \pm 0.03$ & $2.44 \pm 1.77$ \\
185 & $17.10 \pm 1.01$ & $51.43 \pm 1.62$ & $1.02 \pm 0.12$ & $0.05 \pm 0.01$ & $1.16 \pm 0.24$ \\
213 & $17.15 \pm 1.03$ & $52.29 \pm 1.76$ & $0.96 \pm 0.06$ & $-0.07 \pm 0.01$ & - \\
261 & $17.20 \pm 1.05$ & $50.62 \pm 1.82$ & $0.99 \pm 0.05$ & $0.66 \pm 0.01$ & $1.80 \pm 0.23$ \\
286 & $17.43 \pm 1.09$ & $59.71 \pm 2.01$ & $0.98 \pm 0.06$ & $0.19 \pm 0.01$ & $2.06 \pm 0.15$ \\
307 & $17.87 \pm 1.12$ & $62.30 \pm 2.11$ & $1.09 \pm 0.07$ & $0.27 \pm 0.01$ & $1.80 \pm 0.04$ \\
333 & $18.47 \pm 1.30$ & $66.78 \pm 2.12$ & $1.06 \pm 0.08$ & $0.31 \pm 0.01$ & $1.44 \pm 0.08$ \\
375 & $19.64 \pm 1.51$ & $76.02 \pm 2.31$ & $1.00 \pm 0.07$ & - & - \\
\hline
\end{tabular}

Tarım Bilimleri Dergisi - Journal of Agricultural Sciences 
(Yücel \& Erkoyuncu 2000) bildirilmiştir. Araştırmada kullanılan balıkların başlangıç büyüklüğü Genç et al (1998)'in bildirdiği boy değerleri ile benzerdir, ancak ağırlık yönünden daha büyüktür.

Çalışmanın sonlandırıldığı dönemde, balıklar ikinci yaşını tamamlamıştır. Balıkların çalışmanın sonunda ulaştığ rastlanmadığ 1 için karşılaştırma yine literatüre bağlı olarak yapılmıştır. Karadeniz'de iki yaşını tamamlayan Trachurus mediterraneus için ortalama boy daha önce $13.77 \mathrm{~cm}$, ağırlık $19.21 \mathrm{~g}$ (Şahin et al 2009), Trachurus trachurus için ise bu değerler $14.68 \mathrm{~cm}$ ve $27.70 \mathrm{~g}$ (Yücel \& Erkoyuncu 2000) olarak bildirilmiştir (Çizelge 2). Araştırmada ölçülen değerler, her iki istavrit türü için bildirilen değerlerden oldukça yüksektir. Karadeniz'de doğal olarak yaşayan ve büyüyen istavrit balıklarının, elde ettiğimiz değerlere ulaşmaları; Trachurus mediterraneus için yaklaşık 5 yıl (Şahin et al 2009), Trachurus trachurus türü için ise 7 yıl (Yücel \& Erkoyuncu 2000) gerektirmektedir. Doğal olarak balıkların su sıcaklığının düşmeye başladığı kış döneminde yem alımını azaltmaları ve açık denizde sürüler halinde yaşarken besin için rekabet etmeleri ve avlanmak için enerji harcamaları büyüme performansını kültür ortamında stoklanan bireylere göre olumsuz etkilemektedir. Doğal besinlerin enerji içeriklerinin yapay yeme göre oldukça düşük olması ve yem tüketimi için çok daha az enerji harcanması ve predatörlerden kurtulmak için harcanması için gereken hareket enerjisinin büyümeye ayrılması, büyümeyi olumlu yönde etkilemektedir.
Balıkların iyi beslenip beslenmediklerinin diğer bir göstergesi kondisyon faktörüdür. Aylık olarak hesaplanan kondisyon faktörünü Şahin et al (2009) Trachurus mediterraneus için Ağustos ayında dişi bireylerde 1.007; erkek bireylerde 0.936; Genç et al (1998) ise bu değerleri en düşük Nisan ayında 0.73 , en yüksek Ekim ayında 0.83 olarak bildirmiştir. Bostancı (2009) tarafından bildirilen ortalama kondisyon faktörü ise 0.99 'dur. Trachurus trachurus türü için bildirilen ortalama kondisyon faktörü değerleri 0.808 (Satılmış \& Erdem 2008); 0.843 (Yücel \& Erkoyuncu 2000) ve 0.805 (Samsun et al 2006) olarak hesaplanmıştır. Bu projede hesaplanan kondisyon faktörü değerleri en düşük Mart ayında 1.05 \pm 0.04 (1.02-1.09) en yüksek Kasım ayında $1.54 \pm 0.09$ (1.43-1.59) olarak belirlenmiştir. Dolayısıyla kültür ortamında balıkların yem alımının en az seviyelere düştüğü kış aylarında bile doğal ortamda bulunan yaş gruplarına göre çok daha iyi beslendikleri ortaya konmuştur.

Daha önce istavrit yetiştiriciliği ile ilgili gerek bilimsel ve gerekse ekonomik bir veri olmadığından dolayı yem değerlendirme oranının sağlıklı olarak tartışılması mümkün gözükmemektedir. Yem değerlendirme oranını etkileyen diğer bir faktör, türe özel yemin hangi biyokimyasal özellikleri taşımasının gerektiğinin ortaya konulamamış olmasıdır. Ancak, istavrit balığının deniz ortamında yaşaması ve karnivor olmaları nedeniyle, beslemede deniz levreği yemi kullanılması tercih edilmiştir. Deniz levreği yeminin istavrit balığının tüm gereksinimlerin ne düzeyde karşılayacağı konusunda kısmen kondisyon faktörü değerleri önemli bilgileri

\section{Çizelge 2- İki yaşındaki istavrit balıklarının boy ve ağırlık değerleri}

Table 2- Length and weight values of horse mackerel species at age 2

\begin{tabular}{lccl}
\hline Tür & Boy $(\mathrm{cm})$ & A ğrllk $(\mathrm{g})$ & Kaynak \\
\hline T. mediterraneus & 13.83 & 20.80 & Genç et al (1998) \\
T. mediterraneus & 13.77 & 19.21 & Şahin et al (2009) \\
T. trachurus & 14.68 & 27.70 & Yücel \& Erkoyuncu (2000) \\
T. trachurus & 12.58 & - & Samsun et al (2006) \\
T. trachurus & 17.90 & 69.90 & Güroy et al (2006) \\
T. mediterraneus & 19.64 & 76.02 & Bu çalı̧̧ma \\
\hline
\end{tabular}


verebilmektedir. Kondisyon faktörünün oldukça yüksek olması, balığın bu yemle iyi büyüdüğünü ve hatta balığın iç organlarında yağlanmaya neden olduğunu göstermektedir. Ticari açıdan önemli olan yem değerlendirme oranları, Karadeniz Bölgesi'nde yapılan çalışmalarda deniz levreğinde 1.16-7.01 (Okumuş et al 1997) ve çipurada 1.4-3.2 (Şahin et al 1999) değerleri arasında değişim göstermiştir. $\mathrm{Bu}$ projede istavrit balıkları için hesaplanan yem değerlendirme oranları 0.83 ile 3.72 arasında değişim göstermiştir. Dolayısıyla istavrit için yem kalitesi ve balık büyüklüğü ve mevsime bağlı yemleme oranı (tüketim miktarı) çalışmaları yapılarak yem değerlendirme oranında iyileşme yapmak mümkün gözükmektedir. Balığın mevsime bağlı olarak birim satış fiyatı ise yem değerlendirme oranının kabul edilebilir seviyelerde olduğunu göstermektedir (Başçınar et al 2013), ancak gelecek yıllarda ortaya çıkabilecek durumları değerlendirebilmek için türe özgü yem ve ekonomik analiz çalışmalarının yapılması düşünülmelidir.

Kültür ortamında diğer en önemli ekonomik kayıp ölüm oranlarının öngörülenden yüksek olmasıdır. Özellikle deniz levreği ve alabalıkta görülen bazı hastalıklar toplu ölümlere yol açmaktadır. Çalışmanın yürütüldüğü kafes alanında yer alan diğer kafeslerde hem alabalık hem de deniz levreği kültürü devam etmektedir. Alabalıklarda ve deniz levreğinde hastalıklara karşı önlem (dezenfeksiyon $\mathrm{vb}$ ) alınırken istavritler için herhangi bir önlem alınmamıştır. Çalışma süresince yaşanan toplam ölüm oranı ise \% 2'nin altında seyretmiştir.

Çalışmada elde edilen bilgilere göre istavrit balığının kültür potansiyelin var olduğu ortaya konmuştur. $\mathrm{Bu}$ çalışmanın ilk bilimsel çalışma olduğu göz önünde tutulduğunda, yapılması gereken çalışmaların oldukça fazla olduğu ve yeni bilgiler ışığında farklı stratejilerin uygulanmasının gerekli olabileceği açıktır.

\section{Sonuçlar}

İstavrit balıklarının doğadan toplanarak kafes ortamına transfer edilebileceği ve yem alımında zorluk göstermeyeceği proje süresince gözlenmiştir.
$\mathrm{Bu}$ sonuca göre istavrit balıklarının semirtme şeklinde yetiştirilebileceği sonucuna varılmıştır.

İstavrit balıklarının aktif yem alımı ve büyüme hızının sıcak dönemde meydana geldiği belirlenmiştir. Balıkların Haziran-Temmuz döneminde gösterdikleri yumurtlama faaliyetinin sona erdiği için doğadan istavrit toplamanın Ağustos ayında yapılmasının daha yararlı olabileceği söylenebilir. Ancak Ağustos ayında uygulanan av yasağı nedeniyle, balıkların sadece kafeslerden oluşan tuzaklar yardımıyla toplanmasının ve orkinos yetiştiriciliğinde olduğu gibi belirli bir kota çerçevesinde hareket edilmesinin daha yararlı olacağı kanaati oluşmuştur.

Ülkemiz yetiştiricilik sektörüne sonradan katılan gökkuşağı alabalığı yerine, istavritin kafeslerde dört mevsim yetiştirilebileceği ve yaz aylarında kafeslerin boş kalmasını önleyebileceği sonucuna varılmıştır.

\section{Teşekkür}

$\mathrm{Bu}$ çalışma Gıda, Tarım ve Hayvancılık Bakanlığı Tarımsal Araştırmalar ve Politikalar Genel Müdürlüğü tarafından desteklenmiş olan TAGEM-10/AR-GE/19 nolu projeden üretilmiştir. Projenin hayata geçirilmesinde ve çalışmalarında üstün gayret gösteren DOKABAŞ Genel Müdürü Sayın İbrahim BİBEROĞLU'na teşekkür ederiz.

\section{Kaynaklar}

Başçınar N, Altınok İ, Köse S, Akhan S, Alsan Ş, Sonay F D, Şahin Ş A, Şahin A, Tufan B, Boran H, Erbaş H İ \& Civelek R O (2013). Doğu Karadeniz Bölgesi'nde İstavrit Balığı (Trachurus mediterraneus Steindachner, 1868) Yetiştiriciliği, GTHB Tarımsal Araştırmalar ve Politikalar Genel Müdürlüğü, Proje no: TAGEM-10/AR-GE/19. Trabzon, $104 \mathrm{~s}$

Boran H, Terzi E, Altınok İ, Çapkın E \& Başçınar N (2013). Bacterial diseases of cultured Mediterranean horse mackerel (Trachurus mediterraneus) in sea cages. Aquaculture 396(1): 8-13

Bostanc1 D (2009). Sarıkuyruk istavrit, Trachurus mediterraneus (Steindachner, 1868)'un otolit özellikleri ve bazı populasyon parametreleri. $F \ddot{U} F e n$ Bilimleri Dergisi 21(1): 53-60 
Çelikkale M S, Düzgüneş E \& Okumuş İ (1999). Türkiye Su Ürünleri Sektörü Potansiyeli, Mevcut Durumu, Sorunları ve Çözüm Önerileri, İstanbul Ticaret Odası Yayınları No: 1999-2. İstanbul, $414 \mathrm{~s}$

Düzgüneş E \& Karaçam H (1991). Some population aspects, meat yield and biochemical composition of Mediterranean horse mackerel, Trachurus mediterraneus (Steindachner, 1868) in the Black Sea. Doğa-Turkish Journal of Zoology 15: 195-201

Erdem M E \& Bilgin S (2005). Tuzlama ve marinasyon yöntemleri ile işlenmiş istavrit balığının (Trachurus mediterraneus, Steindachner, 1868) muhafazası sırasındaki kalite değişimleri. $O M U ̈$ Ziraat Fakültesi Dergisi 20(3): 1-6

Genç Y, Zengin M, Başar S, Tabak İ, Ceylan B, Çiftçi Y, Üstündağ C, Akbulut B \& Şahin T (1998). Ekonomik Deniz Ürünleri Araştırma Projesi Sonuç Raporu. Proje No: TAGEM/IY/96/17/3/001. Su Ürünleri Merkez Araştırma Enstitüsü, Trabzon, $127 \mathrm{~s}$

Güroy D, Kahyaoğlu G, Özen Ö \& Tekinay A A (2006). Çanakkale Boğazı ve civarında yakalanan istavrit balığının bazı biyolojik özellikleri. E Ü Su Ürünleri Dergisi 23(Ek Say1 1): 91-93

Kartal M, Kurucu S, Aslan S, Özbay Ö, Ceyhan T, Sayar E \& Cevheroğlu Ş (2003). Comparison of w-3 fatty acids by GC-MS in frequently consumed fish and fish oil preparations on the Turkish market. FABAD Journal of Pharmacy Science 28: 201-205

Korkmaz A Ş \& Kırkağaç M (2008). Tatlı suda beton havuzlarda ve denizde ağ kafeslerde yetiştirilen gökkuşağı alabalıklarının (Oncorhynchus mykiss) et verimi, vücut kompozisyonu ve enerji kapsam1. Tarım Bilimleri Dergisi-Journal of Agricultural Sciences 14(4): 409-413

Okumuş I, Küçük E, Başçınar N, Şahin T \& Akbulut B (1997). Deniz levreği (Dicentrarchus labrax) yavrularının doğu Karadeniz koşullarında büyüme performansı. Akdeniz Balıkçılık Kongresi, Bildiriler: 9-11 Nisan, İzmir, s. 277-282

Özdemir S, Erdem Y, Erdem E \& Özdemir Z B (2009). Dip trolü ile farklı av sahalarından avlanan karagöz istavrit (Trachurus trachurus, L.) ve lüfer (Pomatomus saltatrix, L.) balıklarının av verimi ve boy kompozisyonlarının karşılaştırılması. C B $\ddot{U}$ Fen Bilimleri Dergisi 5(1): 19-26

Patır B \& İnanlı A G (2005). Elazığ'da taze olarak tüketime sunulan istavrit (Trachurus mediterraneus, S. 1868) balıklarının mikrobiyolojik kalitesi ve TMA-N değerleri. $F \ddot{U}$ Fen ve Mühendislik Bilimleri Dergisi 17(2): 360-369

Samsun N, Kalayc1 F, Samsun O \& Bilgin S (2006). Samsun Körfezi'nde avlanan istavrit (Trachurus trachurus L., 1758) balığının bazı biyolojik özelliklerinin belirlenmesi. E Ü Su Ürünleri Dergisi 23(3): 481-486

Satılmış H H, Gordina A D, Bat L, Bircan R, Çulha M, Akbulut M \& Kideys AE (2003). Seasonal distribution of fish eggs and larvae of Sinop (the Southern Black Sea) in 1999-2000. Acta Oecologica 24(Supl 1): 275280

Satılmış H H \& Erdem Y (2008). Orta Karadeniz kıyılarında ekonomik değere sahip küçük pelajik balıkların bazı populasyon parametreleri. F $\ddot{U}$ Fen ve Mühendislik Bilimleri Dergisi 20(2): 279-288

Şahin T, Akbulut B, Çiftçi Y, Aksungur M, Erteken A \& Aksungur N (1999). Karadeniz'de Çipura Balığ1 (Sparus aurata L., 1758) Yetiştiriciliği Proje Sonuç Raporu. TKB Su Ürünleri Merkez Araştırma Enstitüsü, Trabzon, $39 \mathrm{~s}$

Şahin C, Kasapoğlu N, Gözler A M, Kalaycı F, Hacımurtazaoğlu N \& Mutlu C (2009). Age, growth, and gonadosomatic index (GSI) of Mediterranean horse mackerel (Trachurus mediterraneus Steindachner, 1868) in the Eastern Black Sea. Turkish Journal of Zoology 33: 157-167

TÜİK (2012). 2003-2011 Y11 Su Ürünleri İstatistikleri, Türkiye İstatistik Kurumu, Ankara

Yankova M H \& Raykov V S (2006). Morphological properties of horse mackerel, Trachurus mediterraneus ponticus Aleev, 1956 (Osteichthyes: Carangidae) from the Black Sea. Turkish Journal of Fisheries and Aquatic Sciences 6: 85-91

Yücel Ş \& Erkoyuncu İ (2000). Orta Karadeniz Bölgesi'nde avlanan istavrit (Trachurus trachurus L., 1758)' in populasyon dinamiği. Turkish Journal of Biology 24: 543-552 